\title{
Features and Characteristics of Motorized and Non- Motorized Milling Spindles
}

\author{
Anandkumar, Sachhidanand Reur
}

\begin{abstract}
The Cutting process used in milling is one of the most common type of industrial machining methods. Similar to traditional milling spindles, the motor driven spindles are fitted with an integrated motor, thereby eliminating belts and gears for the transmission of power from the motor to the cutting tools. The innovative machine tools should be highly characterized systems in order to retain the necessary precision, efficiency and reliability. To satisfy their end user's reliability and availability requirements, both the spindle system (Tool/Tool-Holder/ Spindle) and motor tool system need to be configured for their usability and output results. However, the quality of a control device in industrial practice is greatly affected by the spindle cutting output and its reliability. The motor spindles are nothing but the rotating drive shafts which acts as axes for cutting force tools or in machining process for holding cutting instrument. Hence the spindles are one of the important factor in machining tool process and productivity, as these are used to produce parts as well as machines that produce components, which in turn have a significant impact on production levels and quality of products.
\end{abstract}

Key words: Motorized spindles, Non-motorized spindles, High speed milling spindles.

\section{INTRODUCTION}

To a large degree, industrial productivity depends upon the technology where the use of high-frequency motorized milling spindles are used a professional technology to dramatically improve efficiency and reduce productivity costs. On the one side, higher accuracy is also important for the present situation in manufacturing process that is found particularly in the electronic sectors, automotive sectors or machine tool industries. High precision on the other side, is crucial for cutting force science. Today, machine tools are not only limited to human science capabilities with the aid of CNC technology, but are also able to manufacture ultraprecision items to nano scales which are much more quickly.

In machining centers the motor spindle is the one of the main mechanical cutting tool feeding component. Since the shaft of the motor spindle which rotates at various speeds and carries a cutter tool that mills a rough material that attached to the table of the machining tool.

Revised Manuscript Received on April 13, 2020.

* Correspondence Author

Anandkumar*, Mechanical Engineering Department, Bheemanna Khandre Institute of Technology, Bhalki \& Affiliated to Visvesvaraya Technological University, Belagavi, INDIA. Email: anandtelang75@gmail.com

Dr. Sachhidanand Reur, Industrial and Production Engineering Department,Poojya Doddappa Appa College of Engineering, Kalaburagi, INDIA. Email: sr.chidu1@gmail.com

(c) The Authors. Published by Blue Eyes Intelligence Engineering and Sciences Publication (BEIESP). This is an open access article under the CC BY-NC-ND license (http://creativecommons.org/licenses/by-nc-nd/4.0/)
The spindle's static as well as dynamic stiffness directly affects the workpiece's machining efficiency and finish consistency. The spindle's structural properties depend on the shaft length, the motor, tool holder, bearings mounted on either ends of the spindle and the overall assembly design of spindle configuration. The bearing mounting arrangements are determined by the type of operation, the needed force required for cutting and reliability of the bearings.

The rotating spindles which drive shafts will acts as the axes for cutting tools or in machine tools for holding cutting instruments. The motor spindles are important in manufacturing and also in machine tools, as these are used to produce certain parts as well as machines that produce components, which in turn have a significant impact on production levels and quality of products. There is an growing need for higher precision in machined components, but so is the need for reduced cycle time. Unwanted deflection of the tool, particularly with long slender tools, is caused by high process speeds that generate strong deflecting forces.

High speed spindles are the most critical part of any kind of fast machining process today. The use of these high speed spindles also increases the efficiency for all sorts of machining operations, whether in the CNC process and the machining center or other process components. Usage of high-speed spindles has become a "norm" for all manufacturers in this fast-growing world to stay ahead of competitors. High-speed spindles are considered as the most important elements of high-speed machine tools and are typically very expensive.

Motorized spindles were designed to attain high speed rotation. A model of motor spindle is fitted with an spindle shaft in term it is having integral parts with an integral motor, by removing the need for traditional transmission of power devices such as gears, pulleys and belts. This kind of arrangement eliminates wear and tear and oscillations of the cutting tool, maintains a high rotational equilibrium. This allows the tool with more precise control of increase or decrease in the speed of the shaft. Nevertheless, the high rotational speeds of the shaft with built-in engine often add significant quantity of increase in temperature and chatter formation, which requires correctly control of cooling system by desired lubrication and also proper balancing.

\section{MOTORIZED MILLING SPINDLES}

Today, milling machines with motorized spindles are commonly used for heavy duty milling in all milling centres.

\section{Published By:}

Blue Eyes Intelligence Engineering

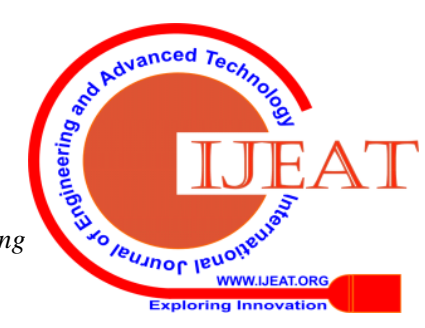


There are several specifically built-in motorized spindles, which are used primarily for a very high friction milling process, while some other motorized spindles are used for all forms of machine tool applications, including drilling, cutting, etc. Compared to belt driven or gear driven spindle shafts, the use of motorized spindles are more convenient in most of the cases and they are specifically considered for optimum friction efficiency and versatility. The higher potential speeds that the motor provides ensure efficient and economical means of machining varying from smaller to larger process of work. These are quite ideal for less precise cutting as well as for detailed finishing. Figure 1 shows the arrangement of the motorized milling spindle.

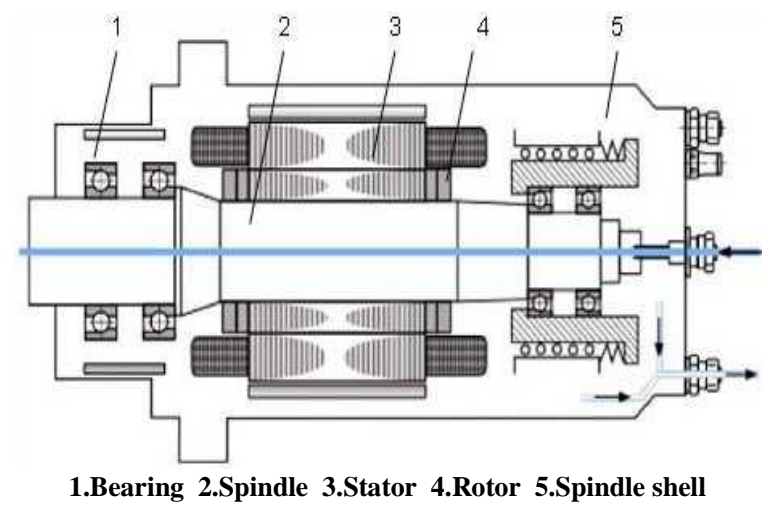

Figure 1. Configuration of Spindle attached with motor.

\section{A. Spindles with Integral Motors}

In machining centers the spindle shaft which holds the cutting tool is considered as one of the main mechanical component. The spindle shaft which rotates at various speeds carries a cutter tool that mills a material attached to the table of the machine tool. The spindle's static and dynamic stiffness directly affects the workpiece's machining efficiency and finish consistency. The spindle's structural properties directly depend upon the shaft length, motor speed, tool holder configuration, bearings arrangements and the overall spindle assembly design procedure. Static stiffness is known to maximize the span of the bearings using two bearings for design optimization of the spindles. Additionally, the majority of optimizing design considerations such as diameter of shaft, span and preload of bearings are taken into consideration to reduce the static deflection.

Integral motor spindles as part of the rotor shaft have to use an electrical motor. Hence, the size and efficiency of the motor will strongly depend on the space available. The loading power, stiffness and maximum speed are also influenced by the bearing size, so the motor specifications have to suit the bearing life to withstand the strength.

AC induction type motor is the most common used in machine loaded spindles. With help of a thermal clamping or an adhesive the rotor is mounted on the spindle shaft in this system. In general, the motor or drive manufacturer supplies the stator and rotor assembly with the winding in which the rotor spins. During assembly the rotor is fastened to the shaft. The bearings are then mounted at the either ends of the shaft that is at both front and rear ends of the shaft and then the shaft is placed into the spindle casing arrangement.
The motor spindle shaft is very critical as the power has to be transferred from the motor to the cutting instrument. The shaft must find and support the bearings, as well as carry the entire tooling device. Bending is one of the key design criteria for the pipe. The shaft will exhibit bending characteristics during high velocity operation. The rate of vibration at which the shaft deflects depends upon the diameter of the spindle shaft and its length. For designing a high length spindle shaft is also appealing, as it will increase the spindle's load handling ability and it can lead to make a more powerful motor. Nevertheless, caution must be taken as the length of the spindle increases; the first mode of bending characteristics in the operating zone may reach undesirable frequencies. For spindle operation, this kind of approach is not acceptable and should be overcome either by rearrangement of the shaft with a increase in diameter (bearings would be smaller and larger) or even by reducing the length of the shaft.

\section{B. Motorized Milling Spindle Features}

- One of the basic features of this kind of spindle design is that it will help in minimizing product time cycle.

- It is considered for completing the machining, in only single clamping configuration.

- The motor spindle model is also available for multifunctional spinning, drilling and frictional modules.

- The spindle can change cutting tool automatically which provides reliability and flexibility.

- Motorized spindles ensures non- machining of large variety of workpiece materials.

- In-built motor configuration prevents gearing and pulley problems.

- The rotational motion in these motor spindles is achieved by using the torque motor as a direct drive configuration.

- Lower velocity Friction.

- Overall high rigidity.

\section{Technical specifications}

- Continuous power availability

- Spindle power

- Spindle torque

- Motor size

- Type of bearing

- Lubrication form Radial and axial tolerance

- Cooling

- Front bearings

- Interface of the tool

- Weight, etc.

\section{NON-MOTORIZED MILLING SPINDLES}

The belt powered milling spindles are another common category of milking spindles. Such spindles are, as the name implies, powered by a tangential belt system and commonly used for milling and engraving applications.

Published By: DOI: 10.35940/ijeat.D7433.049420
Blue Eyes Intelligence Engineering

\& Sciences Publication

(C) Copyright: All rights reserved. 
They are available in various sizes, with a wide range of speed and power. With their design versatility, variety and efficiency, the belt-driven friction spindles are suitable for a wide range of milling applications.

\section{A. Characteristics of Non-Motorized Spindles and its varying parameters}

1. Selection of Transmission types: There are variety ranges of forms in transmission, as the torque is getting transferred to the spindle shaft from the motor. The key configurations for the system are gear, belt-pulley, direct coupling and motorized types. Such forms are summarized in the following table 1 .

Table 1. Typical transmission properties [16]

\begin{tabular}{|c|c|c|c|c|c|c|c|c|c|}
\hline & Torque & Speed & Accuracy & Maintainability & & $\begin{array}{l}\text { Dynamic } \\
\text { t Stiffness }\end{array}$ & Noise & $\begin{array}{c}\text { Replacemen } \\
\text { Time }\end{array}$ & \begin{tabular}{|l|} 
Therma \\
Effect
\end{tabular} \\
\hline Gear & (0) & $X$ & & & $\triangle$ & ) & X & $\triangle$ & \\
\hline Belt, Pulleys & 0 & $\triangle$ & $\triangle$ & & & & $\triangle$ & $\triangle$ & \\
\hline Direct coupling & $\triangle$ & 0 & & & & & & $\triangle$ & \\
\hline Motorized & $\triangle$ & (0) & (0) & $\triangle$ & & $\triangle$ & (2) & (0) & $\triangle$ \\
\hline
\end{tabular}

2. Gear type: A wide range of spindle speeds and torque are needed to suit a cutting condition. Heavy milling operation requires very high torque. Therefore, torque reduction via a gear system is used. The torque transmitted to the motor is reduced proportional to the speed reduction. Through increasing the gear ratio, the spindle's torque range will be increased corresponding to the gear ratio without altering the motor spindle strength. If both spindle and motor gear size are exactly the same, the torque of the spindle becomes as the torque generated by the spindle motor. But in terms of speed, they are operated at lower rpm and even noisier during operation.

3. Belt-Pulley type: Belt-pulley type spindles are commonly used at high spindle speed ranges, i.e. up to 8000 rpm. However, belt cannot transmit much torque because of the slip between the belt and the pulley interface. Moreover, at the spindle range of more than $8000 \mathrm{rpm}$, the belt heats up and expand, leading to the loosening of transmission tension and hence the sufficient torque cannot be transmitted.

4. Direct Coupling type: For the spindle torque and speed range which cannot be driven by the belt-pulley mechanism, the direct coupling type spindle is used. The maintainability of a separated motor for the spindle is advantageous if one of the bearings is broken, either the spindle or the spindle motor can be independently repaired. At higher speed range, however the improper arrangement between the coupling and motor spindle or the spindle shaft results in repeated vibrations.

5. Motorized type: The Motorized type spindle is one where the motor is directly integrated to the spindle shaft. In the absence of transmission linkage between the spindle and the motor, there will be less unbalanced forces and distortion. However, because of the built-in motor structure, the bearing span between the front and rare bearings tends to

Retrieval Number: D7433049420/2020@BEIESP

DOI: 10.35940/ijeat.D7433.049420

Journal Website: www.ijeat.org be wider and spindle shaft also tends to be longer. Therefore the static stiffness of the spindle shaft plays a vital role at higher speeds.

\section{B. Varying parameters for different configurations}

Different parameters influence the milling spindles from the performance point of view are stated as follows.

1. Specification of Torque and Power required for the Cutting: From the given cutting conditions, the necessary cutting torque is evaluated and compared to the requirements of the motor spindle. The torque required for cutting is measured instantly on the basis of cutting mechanics rules. Figure 2 summarizes the relation of torque and power with regard to motor rpm.

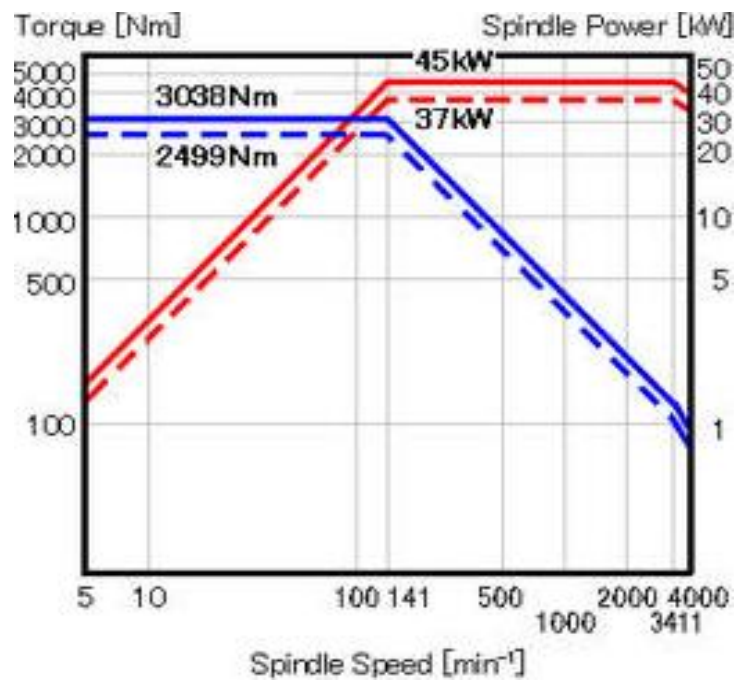

Figure 2. Power and torque diagram

2. Specification of Spindle Motor: To define the type of transmission, the spindle motor requirements have to be determined. Accordingly, the relationship between the torque and power of the motor should be determined.

3. Classification: The specifications of the spindle motor are verified by the application of the maximum torque required for cutting and its respective speed of the spindle needed. Check whether the maximum torque required for cutting is less the torque of the motor. Also check if the motor's peak speed is greater than the spindle speed used in targeting the machining operations. The required torque of the spindle and the maximum speed of the spindle are expressed respectively. If the torque and speed needed to achieve the machining operation are greater than the motor's capability, then the design changes are inevitable.

4. Choice between type of Belt-Pulleys and Gear types: The transmission between the belt-pulley and gear types is calculated by referring to the configuration and placements of the bearing range. Compared with the gear, the beltpulley type can't transmit significant torque. The torque can be low, medium or high. The centrifugal force affects the belt to expand at high speeds which prevents large torque transmission. Therefore the transmissions of power through gear or belts are typically not suitable at a certain speed range of spindles greater than $15000 \mathrm{rpm}$.

Published By:

Blue Eyes Intelligence Engineering \& Sciences Publication

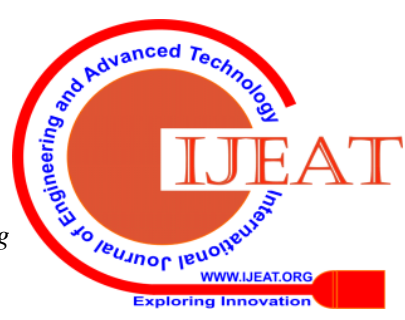


Due to these limitations, the belt-pulley or gear type of transmission is chosen, only for lower and middle range of speeds.

5. Low cost versus High precision: Owing to their simplicity, the belt transmission components can be produced at low costs where as the manufacturing of gears is more expensive due to their difficulty of design involved. Whereas on the other side, the spindle shaft deflects as the belt tension is applied at the pulley's end and the motor spindle rotational accuracy is not as good as the gear form.

The traditional spindle design method is affected by a large number of parameters, such as length of spindle shaft, collars and housing. However, to maximize the design parameters of spindle in practice, the most efficient design parameters have to be chosen. The architectural spindle design parts and dimensions for design are subject to various constraints are typically taken care with respect to each other. For example, if the spindle shaft diameter changes, it is also important to adjust the bore diameter of the housing. Thus the further design parameters are taken into consideration which has the tendency to converge the problem in the optimization of the design problems.

\section{Belt-Powered Spindle Features}

- The majority of belt-driven milling spindles are made from high-quality steel for proper robustness and balance during operation.

- They are structured, dynamically.

- Variable rpm can be accomplished by the use of stepped pulley or pulley adjustments.

- Increased rigidity is given for the belt driven friction spindle bearing system. They are suitable for the combination of mild to extreme radial and thrust loading associated with milling cutters.

- The spindles are arranged for front and rear air purges.

- They're designed as a device interface with a friction taper.

- The spindles are separated by spindle shaft with hole.

- The type of the housing can be tube, flanged tube, foot mount or type of block.

\section{Technical specifications}

- Type of bearing

- Lubrication

- Device interface

- Belt type

- Housing style

- Diameter of the housing

- Cooling system

- Speed range

- Spindle coolant (CTS)

- Spindle splash Ring

- Stability achieved

- Friction spindle length and diameter

- RPM range, etc.

\section{HIGH FREQUENCY MILLING SPINDLE}

The high speed motorized spindle, which incorporates combines spindle tool and motor drive to provide with belt transmission and gear transfer, effectively fosters the development of machine tool technology. The motorized spindle with greater speeds has become an important functional unit of machine tools which attain higher speeds and their output affects machine tool production. The high speed rotational spindle shafts have increased tremendously in recent years. The later developments with more power or torque put at the higher speeds has forwarded the more stringent need for high speed spindle output, particularly the dynamic behavior that affects the precision of machining, reliability and efficiency of production. Hence the dynamic performance research was more significant. The motorized high frequency milling spindle configuration is as shown in Figure 3.

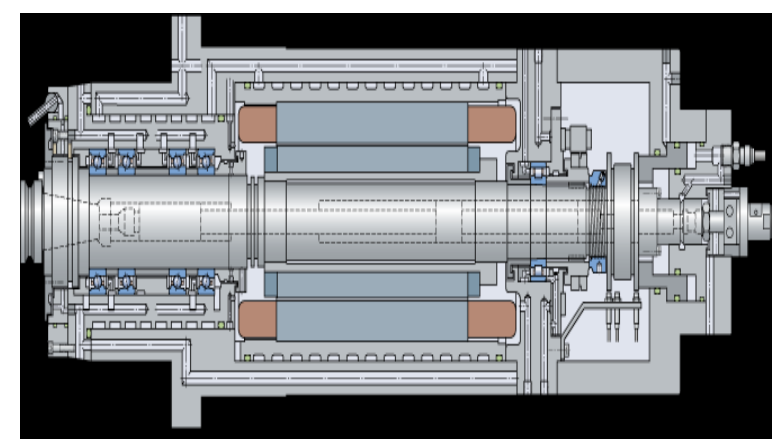

Figure 3. Arrangement of High frequency Milling Spindle

Currently, high speed spindle with static and dynamic output work based on theoretical modeling and simulation of finite elements are under process for achieving the machining standards. Many research techniques are developed as a model of the spindle-bearing machine tool mechanism based on a finite element methods, fuzzy methods, chatter stability characteristics, micro and macro end milling processes, etc. All these studies are based on the dynamics behavior of the spindle shafts at quite higher speeds.

Spindles for milling can be powered at high frequency. The highly driven friction spindles are very commonly used spindle category and are recommended to higher level in the high speed frictional and design principles. Also these spindles are increasingly being used in machining centres for higher metal removal rate, due to their feasibility to work at greater power and sufficiently at higher speeds.

\section{A. High Frequency Milling Spindle Features}

The following are some of the features most commonly available in motor spindles with high frequency.

- High torque value of those spindles.

- They are highly strong.

- Extremely high rotational speed.

- The axial stiffness values are very high.

- The high values of radial stiffness.

- The rate of metal removal is higher than for other spindles.

- Portable in nature, generally.

- Many have control sensors for angular position and speed.

- Automatic Device Shift Provision program.

Published By:

Blue Eyes Intelligence Engineering DOI: 10.35940/ijeat.D7433.049420

Journal Website: www.ijeat.org

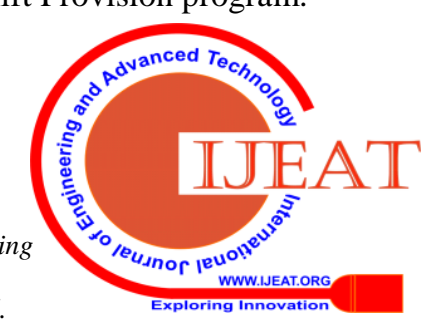

\& Sciences Publication

(C) Copyright: All rights reserved. 
- Temperature sensors •

- These are accelerometers which can communicate with a broad variety of drives and frequency converters.

\section{Technical specifications}

The following are other considerations to be considered for the purchase of high-frequency milling spindles.

- Torque

- Top speed

- Preload

- Lubrification: air or oil

- External diameter

- Length

- Type of spindle

- Strength of coolant

- Power

\section{B. Major Components}

Figure 4 shows the major components that are needed for Precision Spindle design include.

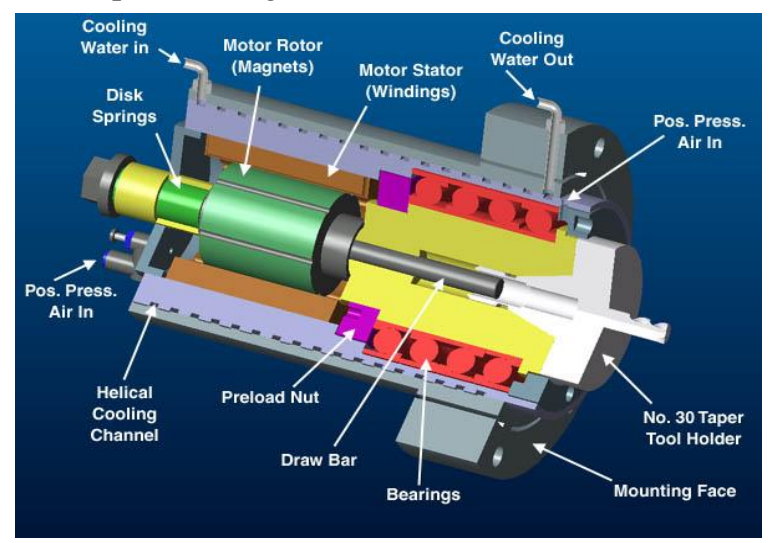

Figure 4. Significant components and structure for Mini-Spindles [20]

Few major components are summarized as;

- Spindle type- Integral Motor with Spindle.

- Bearings for Spindle- Quantity, Mounting, type and Lubrication process.

- Motor spindle shaft- Tool retention drawbar for shaft and cutting tool used.

\section{Spindle Features}

The spindle has several features that allow it to attain high precision at low cost. Our maximum spindle speed planned for the Mini-Mill prototype and low cost models is 12,000 rpm. A stock frameless motor is directly mounted on the shaft and within the spindle casing. It reduces the weight and cost of a separate motor housing. The bulk needed to mount the motor on one side is removed by mounting the motor on the shaft. The downside of this design is that the motor must be capable of achieving the top speed of the spindle. If mounted on one side, and the shaft was driven by a belt and pulley, the motor could spin slightly less than the speed of the spindle (pulleys used to gear it up). In the lower speed ranges (less than $6000 \mathrm{rpm}$ ), a lot more stock motors are available.
- Type of coolant

\section{Tooling System}

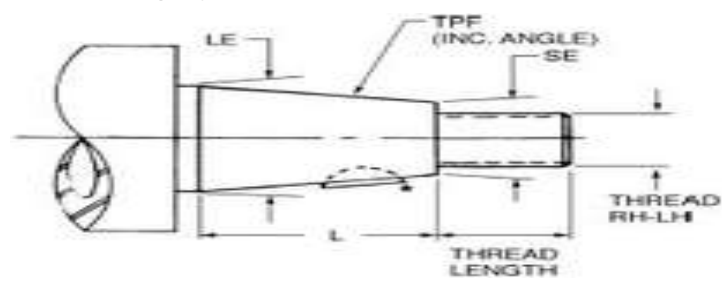

Figure 5. Typical Tool-head

The tool keeping and shift is achieved in the prototype and low cost model by means of a tapered angle head and a manual draw bolt. An automatic tool changer will need to be mounted for a production line version. A typical tool-head is shown in the above figure 5 .

\section{RESULT AND DISCUSSION}

Today the high speed spindles have emerged as the most important component for any kind of high machining process. As compared to the non-motorized milling spindles the motorized milling spindles are have an edge in terms of performance, high end machining with improvised time and precision process. But certain consideration may be overviewed regarding the spindle housing, deflection of the spindle both in terms of static and dynamic. Spindle Bearing Selection is also one of the key factor by taking into consideration of its speed, lubrication for cooling and the bearing arrangements.

If we consider the spindle is water-cooled to allow very robust then the temperature of the spindle is dramatically controlled by the process of water cooled during cutting process and also during chatter formation thereby reducing thermal errors and wear due load on the bearings. Usually the aluminum alloy material is used in building the robust cooling system and housing because its thermal expansion coefficient is three times greater than that of steel. Aluminum as a housing material provides many benefits over stainless steel. Machinery is much cheaper than steel. This also has about twice the thermal conductivity of steel which makes maintaining the housing at a constant temperature simpler. The relation between aluminum and steel is illustrated in below figure 6 .

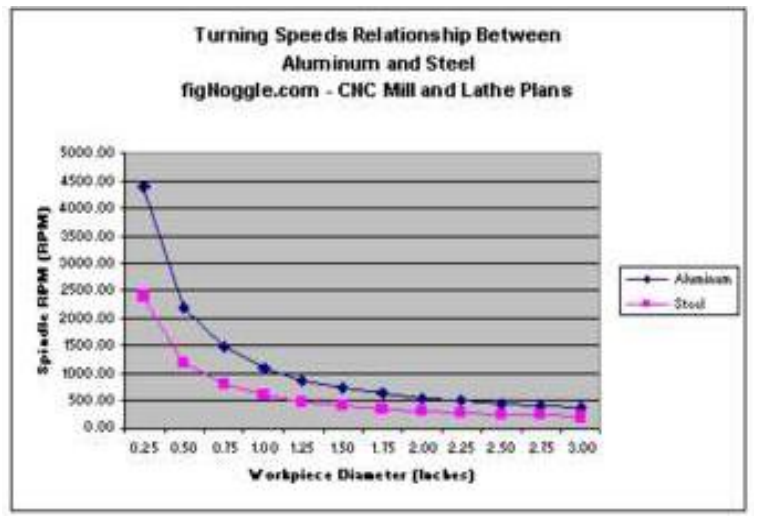

Figure 6. Comparison of Aluminum and Steel housing for cooling.

Published By:

Blue Eyes Intelligence Engineering

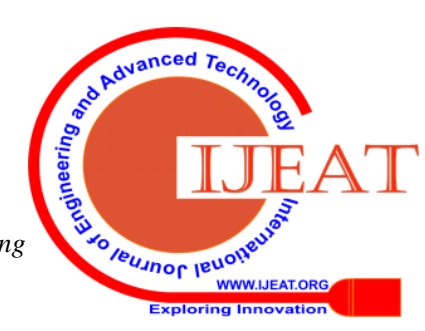

\& Sciences Publication 


\section{CONCLUSION}

1) Consideration may be given in overcoming the problems of improper loading on bearings and measurement of dynamic output of the motorized spindle.

2) The motorized spindles propose an alternative method to the non-motorized milling spindles in terms of achieving greater speeds and effective cutting process.

3) The use of belts and pulleys can be eliminated by the use of motorized spindles.

4) The high output speeds that the motor provides ensure efficient and cost effective machining from small scale to the large output of work.

5) They are ideal for accurate finishing and also for rough cutting process.

\section{REFERENCES}

1. Denghui Li, Hongrui Cao, Jinxin Liu, Xingwu Zhang, Xuefeng Chen "Milling chatter control based on asymmetric stiffness", ElsevierInternational journal of Machine Tools \& Manufacture 147 (2019) 103458.

2. Shaoke Wana, Xiaoliang Jin, Naresh Kumar Maroju, Jun Hong "Effect of vibration assistance on chatter stability in milling", Elsevier- International Journal of Machine Tools and Manufacture 145 (2019) 103432.

3. H. Cao, X. Zhang, X. Chen "The concept and progress of intelligent spindles”, a review, Int. J. Mach. Tool Manuf. 112 (2017) 21-52.

4. CutPro TM module for spindle analysis, 2013. Manufacturing Automation Laboratories Inc. (MAL). URL: http://www.malinc.com/spindlepro.html.

5. Eike Foremny, Christian Schenck, Bernd Kuhfuß "Dynamic behavior of an ultra precision spindle used in machining of optical components", Elsevier- ScienceDirect Procedia CIRP 46 ( 2016 ) 452-455.

6. Xiaopeng Wang, Yuzhu Guo, Tianning Chen, Xi'an Jiaotong "Measurement Research of Motorized Spindle Dynamic Stiffness under High Speed Rotating”, Research Article Xi'an 710049, China Accepted 3 February 2015.

7. Jakeer Hussain Shaik and K. Ramakotaiah "Designing of milling tool spindle", Bangladesh Journal of Scientific and Industrial Research 53(3), 191-198, 2018.

8. A. S. Delgado, E. Ozturk, N. Sims “Analysis of Non-Linear Machine Tool Dynamic Behavior", Elsevier- ScienceDirect Procedia Engineering 63 (2013) 761-770.

9. F. Shi, H. Cao, X Zhang, X. Chen "A chatter mitigation technique in milling based on H -ADDPMS and piezoelectric stack actuators", Int. J. Adv. Manuf. Technol. 101 (9-12) (2018) 2233-2248.

10. A. Matsubara, T. Yamazaki, and S. Ikenaga "On-contact measurement of spindle stiffness by using magnetic loading device", International Journal of Machine Tools \& Manufacture, vol. 71, pp. 20-25, 2013.

11. Deping Liu, Hang Zhang, Zheng Tao and Yufeng Su "Finite Element Analysis of High-Speed Motorized Spindle Based on ANSYS", The Open Mechanical Engineering Journal, 2011, 5, 1-10.

12. Sébastien Seguy \& Tamás Insperger \& Lionel Arnaud \& Gilles Dessein \& Grégoire Peigné "On the stability of high-speed milling with spindle speed variation", Int J Adv Manuf Technol (2010) 48:883-895 DOI 10.1007/s00170-009-2336-9.

13. Osamu Maeda, Yuzhong Cao, Yusuf Altintas "Expert spindle design system”, International Journal of Machine Tools \& Manufacture, 45 (2005) 537-548, October 2004.

14. Dr.Sinan Badrawy "Dynamic Modeling and Analysis of Motorized Milling Spindles”, Moore Nanotechnology Systems, LLC, 2003.

15. Spindle Concepts and Design- Spindle Motors, literature KAE-S6267.3, Yaskawa Electric Corporation, Tokyo, Japan.

16. Technical Specifications for IBAG-Motor Spindles, IBAG Switzerland AG, 1999, www.ibag.ch

17. CMTI Machine Tool Design Hand Book, Tata McGraw-Hill Company Limited, 1983, 421-588

18. FAG Spindle Bearings Catalogue, AC 41 130/7 EA • March 2008, www.fag.com.

\section{AUTHORS PROFILE}

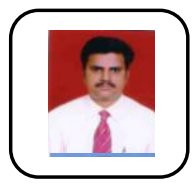

Anandkumar,

Assistant

Professor

BE(Mechanical).ME(Machine Design) Area of Research: Design, FEM Research Papers Published in International Journals: 04 Papers Published in National Conferences:04 Membership of Professional Bodies: ISTE

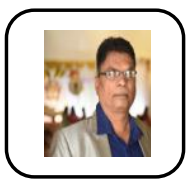

Dr.Sachhidanand Reur, Professor BE(Mechanical),M.Tech(Production),P.hD Areas of Research and Interest: CAD, CAM, Robotics, Virtual Reality, CAPP, Design. Research Papers Published in International

Journals:12 Papers Published in International Conferences:04 Membership of Professional Bodies: ISTE and IE

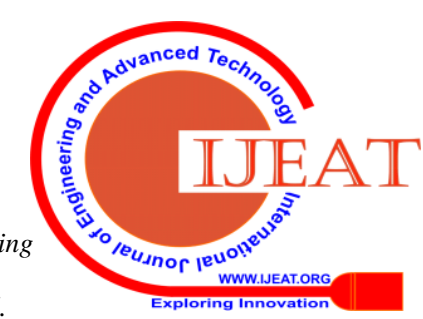

